Supporting Information

\title{
Singlet Oxygen Triggered by Superoxide Radicals in a Molybdenum Cocatalytic Fenton Reaction with Enhanced REDOX Activity in the Environment
}

Qiuying Yi, Jiahui Ji, Bin Shen, Chencheng Dong, Jun Liu, Jinlong Zhang, Mingyang Xing*

Key Laboratory for Advanced Materials and Institute of Fine Chemicals, East China University of Science and Technology, 130 Meilong Road, Shanghai 200237, P.R. China

*Corresponding Author:

Email: mingyangxing@ecust.edu.cn

\section{Table of Contents}

$\begin{array}{ll}\text { 1. Apparent kinetic calculations } & \text { S2 }\end{array}$

2. Figures (2 figures) $\quad$ S4

3. Degradation pathway of L-RhB in Mo co-catalyst Fenton system S6

4. Mechanism of the degradation in Mo co-catalytic Fenton system S10

5. Images of the inactivation of $S$. aureus $\quad$ S16

$\begin{array}{lr}\text { 6. Figures (4 figures) } & \text { S19 }\end{array}$

$\begin{array}{ll}\text { References } & \text { S22 }\end{array}$ 

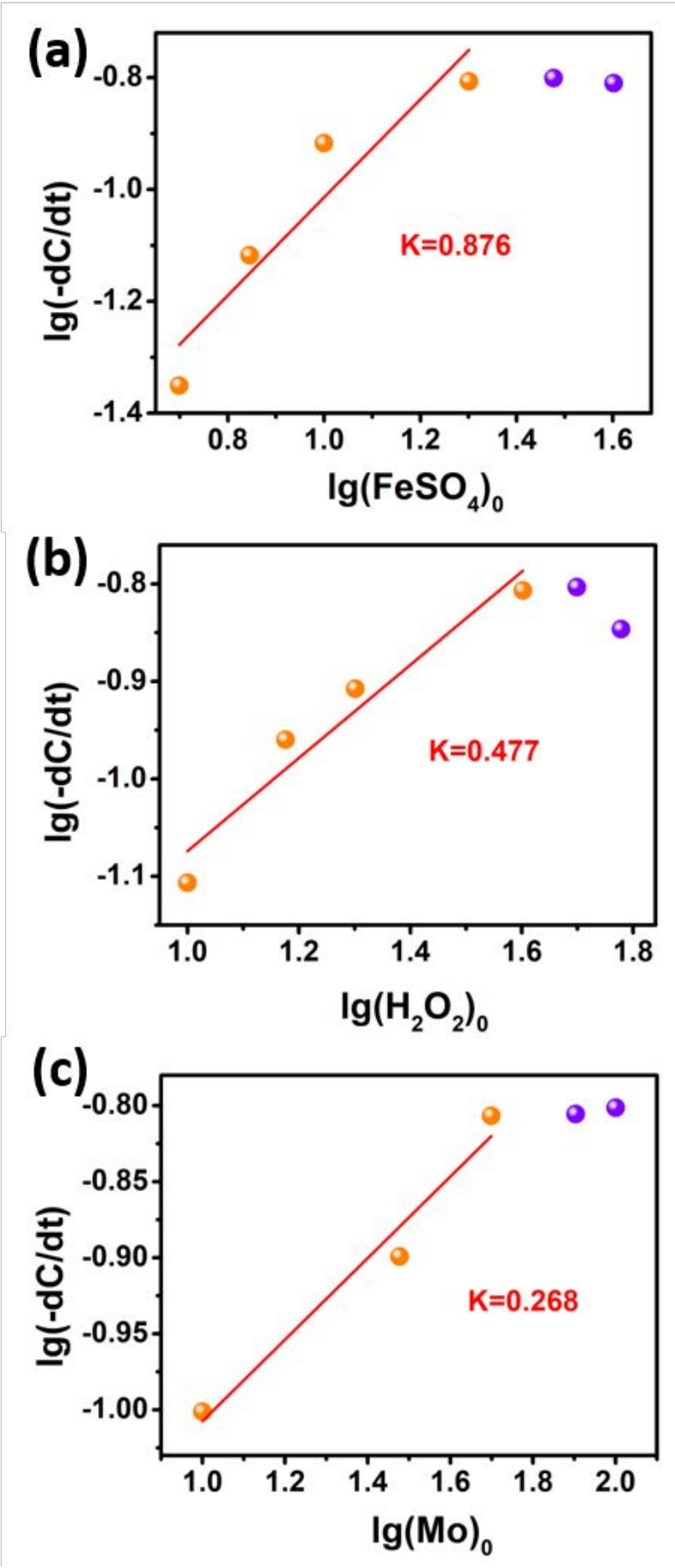

Figure S1. Apparent kinetic calculations. (a) The fitting line between $\lg (-\mathrm{dC} / \mathrm{dt})$ and $\lg \left(\mathrm{Fe}^{2+}\right)_{0}$. (b) The fitting line between $\lg (-\mathrm{dC} / \mathrm{dt})$ and $\lg \left(\mathrm{H}_{2} \mathrm{O}_{2}\right)_{0}$. (c) The fitting line between $\lg (-\mathrm{dC} / \mathrm{dt})$ and $\lg (\mathrm{Mo})_{0}$.

As shown in Figure S1, the reaction rate increased during the amount of $\mathrm{Fe}^{2+}$ increase within a certain scope but have no significant change beyond this range. The $\mathrm{H}_{2} \mathrm{O}_{2}$ and Mo powder have the similar results, but the reaction rate decreased while the $\mathrm{H}_{2} \mathrm{O}_{2}$ was too much. And the equation can 
be described as the following equation (1-2).

$$
\begin{aligned}
& \mathrm{V}=\frac{-\mathrm{dC}}{\mathrm{dt}}=K\left[\mathrm{Fe}^{2+}\right]^{a}\left[\mathrm{H}_{2} \mathrm{O}_{2}\right]^{b}[\mathrm{Mo}]^{c} \\
& \lg \frac{-\mathrm{dC}}{\mathrm{dt}}=\lg K+a \lg \left[\mathrm{Fe}^{2+}\right]+b \lg \left[\mathrm{H}_{2} \mathrm{O}_{2}\right]+c \lg [\mathrm{Mo}]
\end{aligned}
$$

For this analysis, we assumed that the initial concentration of different reactants in the co-catalysis Fenton system is $\left[\mathrm{Fe}^{2+}\right]_{0},\left[\mathrm{H}_{2} \mathrm{O}_{2}\right]_{0}$ and $[\mathrm{Mo}]_{0}$ (equation 3-5). So that we can obtain the fitting line shown in Figure $\mathrm{S} 1$ and the related equation at the $\mathrm{t}=0$ :

$$
\begin{aligned}
& \lg \frac{-\mathrm{dC}}{\mathrm{dt}}=0.876 \lg \left[\mathrm{Fe}^{2+}\right]_{0}-1.89 \\
& \lg \frac{-\mathrm{dC}}{\mathrm{dt}}=0.477 \lg \left[\mathrm{H}_{2} \mathrm{O}_{2}\right]_{0}-1.55 \\
& \lg \frac{-\mathrm{dC}}{\mathrm{dt}}=0.268 \lg [\mathrm{Mo}]_{0}-1.28
\end{aligned}
$$

Based on the above equations (4-6), we can conclude that Mo powder could greatly improve the total reaction rate. 


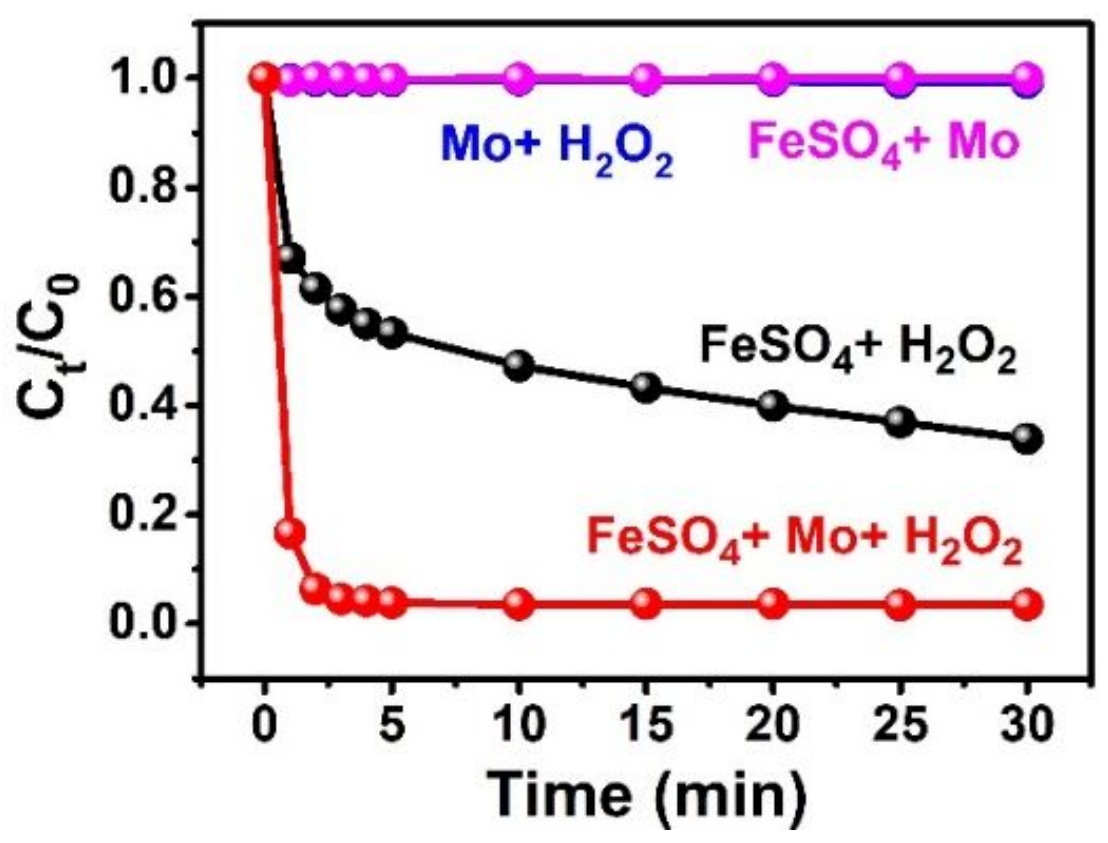

Figure S2. Degradation of L-RhB under different conditions at $30 \mathrm{~min}$. 

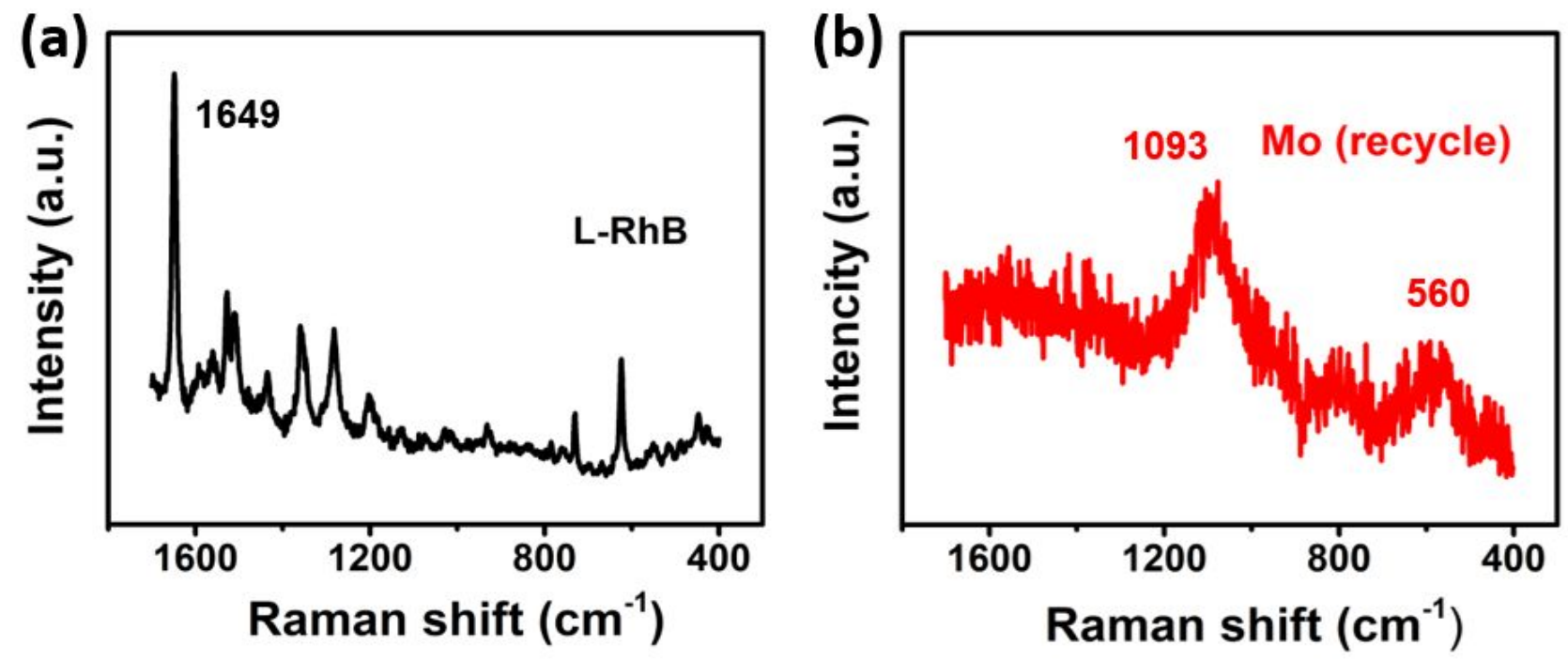

Figure S3. Raman spectrum of (a) L-RhB and (b) Mo recycle after degradation of L-RhB.

The most obvious specific peak at $1649 \mathrm{~cm}^{-1}$ is corresponding to benzene ring of L-RhB, as shown in Figure S3a. And there is no peak at $1649 \mathrm{~cm}^{-1}$ in Figure S3b, which inhibited have no adsorption of L-RhB on Mo powder. The Raman bands at $1093 \mathrm{~cm}^{-1}$ and $560 \mathrm{~cm}^{-1}$ of Mo powder are assigned to the stretching vibrations of the terminal $\mathrm{Mo}=\mathrm{O}$, and we can obtain the conclusion that Mo powder is coated with oxide for the stabilization. 
(a)

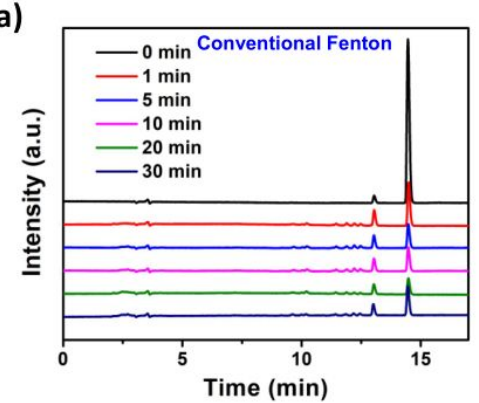

(c)

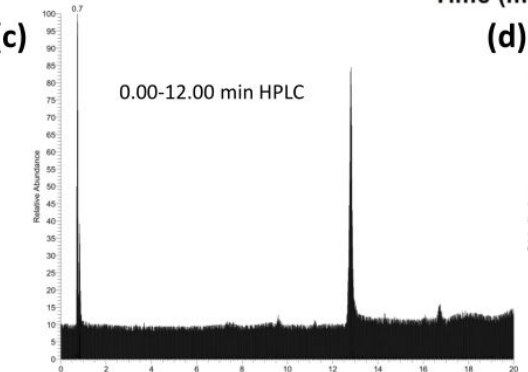

(f)

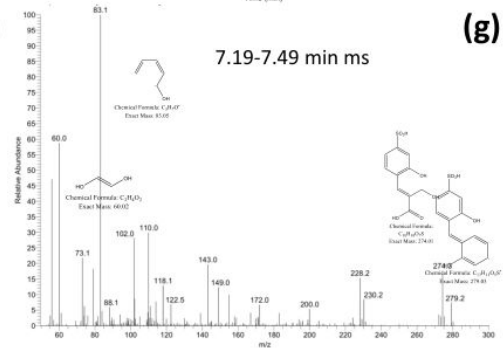

(b)

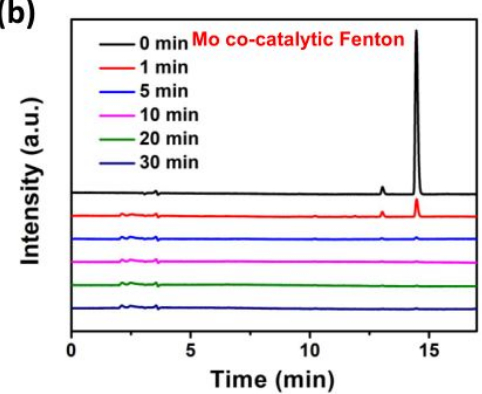

(e) (d)
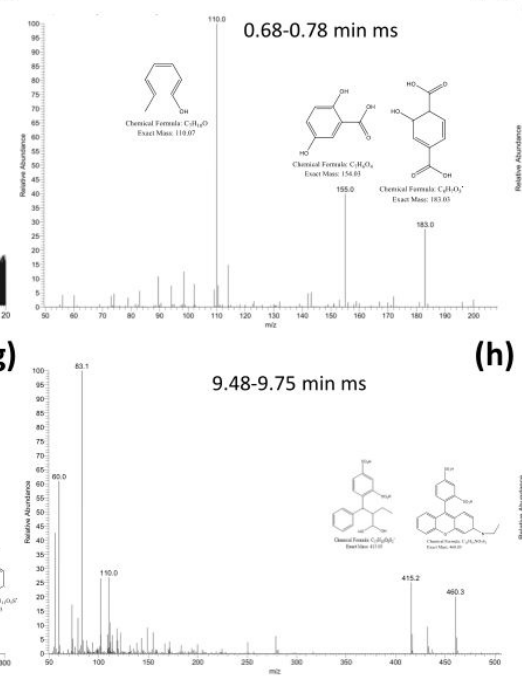

(h)
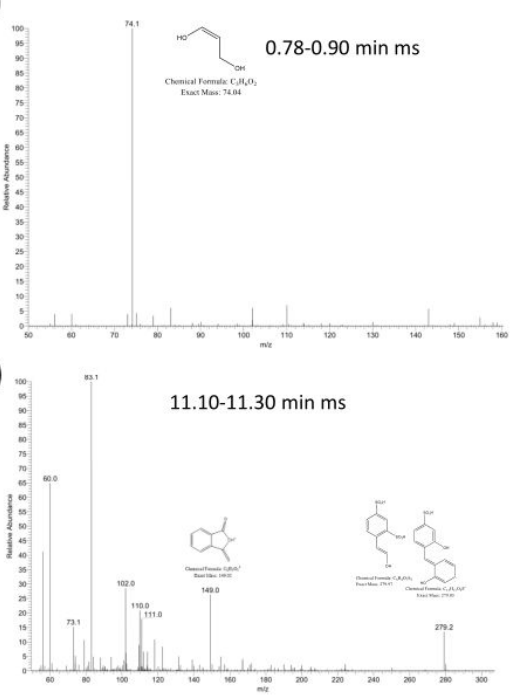

Figure S4. HPLC chromatograms of L-RhB intermediates at different times of (a) conventional Fenton and (b) Mo co-catalytic Fenton. (c) HPLC chromatograms of L-RhB intermediates at 5 min of Mo co-catalytic Fenton. (d-h) MS of five time periods and related main intermediate products in Mo co-catalytic Fenton reaction.

We have tested the HPLC for different reaction times in different systems to compare the intermediate products, as shown in Figure S4a and S4b. In the conventional Fenton system, these intermediates were similar during the 1-30 min degradation process, except the characteristic peak strength of L-RhB decreased. However, in the Mo co-catalytic system, these intermediates were significantly reduced, indicating that organic pollutants were degraded more fully in this system. At the same time, the intermediate at 2-3 min in the Mo co-catalytic system are more than those in the conventional Fenton system (Figure 2c), which are the main production in Mo co-catalytic system. In order to illustrate the specific intermediate product at different detection times, we conduct the HPLC-MS, as shown in Figure S4c-h. Several important intermediates were detected by ion 
chromatography in five time periods. In the first period, $0.68-0.78 \mathrm{~min}$, three main products were detected at m/z 110, 155 and 183, which related with $\mathrm{C}_{7} \mathrm{H}_{10} \mathrm{O}, \mathrm{C}_{7} \mathrm{H}_{6} \mathrm{O}_{4}$ and $\mathrm{C}_{8} \mathrm{H}_{7} \mathrm{O}_{5}$, respectively. In the second period, $0.78-0.90 \mathrm{~min}, \mathrm{~m} / \mathrm{z} 74$ is corresponding with $\mathrm{C}_{3} \mathrm{H}_{6} \mathrm{O}_{2}$. In the third period, 7.19-7.49 $\mathrm{min}$, four main products were detected at $\mathrm{m} / \mathrm{z} 60,83,274$ and 279, which related with $\mathrm{C}_{2} \mathrm{H}_{4} \mathrm{O}_{2}, \mathrm{C}_{5} \mathrm{H}_{7} \mathrm{O}, \mathrm{C}_{10} \mathrm{H}_{10} \mathrm{O}_{7} \mathrm{~S}$ and $\mathrm{C}_{15} \mathrm{H}_{11} \mathrm{O}_{5} \mathrm{~S}$, respectively. In the fourth period, 9.48-9.75 min, two main products were detected at $\mathrm{m} / \mathrm{z} 415$ and 460 , which corresponding with $\mathrm{C}_{17} \mathrm{H}_{19} \mathrm{O}_{8} \mathrm{~S}_{2}$ and $\mathrm{C}_{21} \mathrm{H}_{18} \mathrm{NO}_{7} \mathrm{~S}_{2}$, respectively. In the firth period, 11.10-11.30 min, two main products were detected at $\mathrm{m} / \mathrm{z} 149$ and 279, which corresponding with $\mathrm{C}_{8} \mathrm{H}_{5} \mathrm{O}_{5}$ and $\mathrm{C}_{8} \mathrm{H}_{8} \mathrm{O}_{7} \mathrm{~S}_{2}$ (or $\mathrm{C}_{8} \mathrm{H}_{8} \mathrm{O}_{7} \mathrm{~S}_{2}$ ), respectively. 


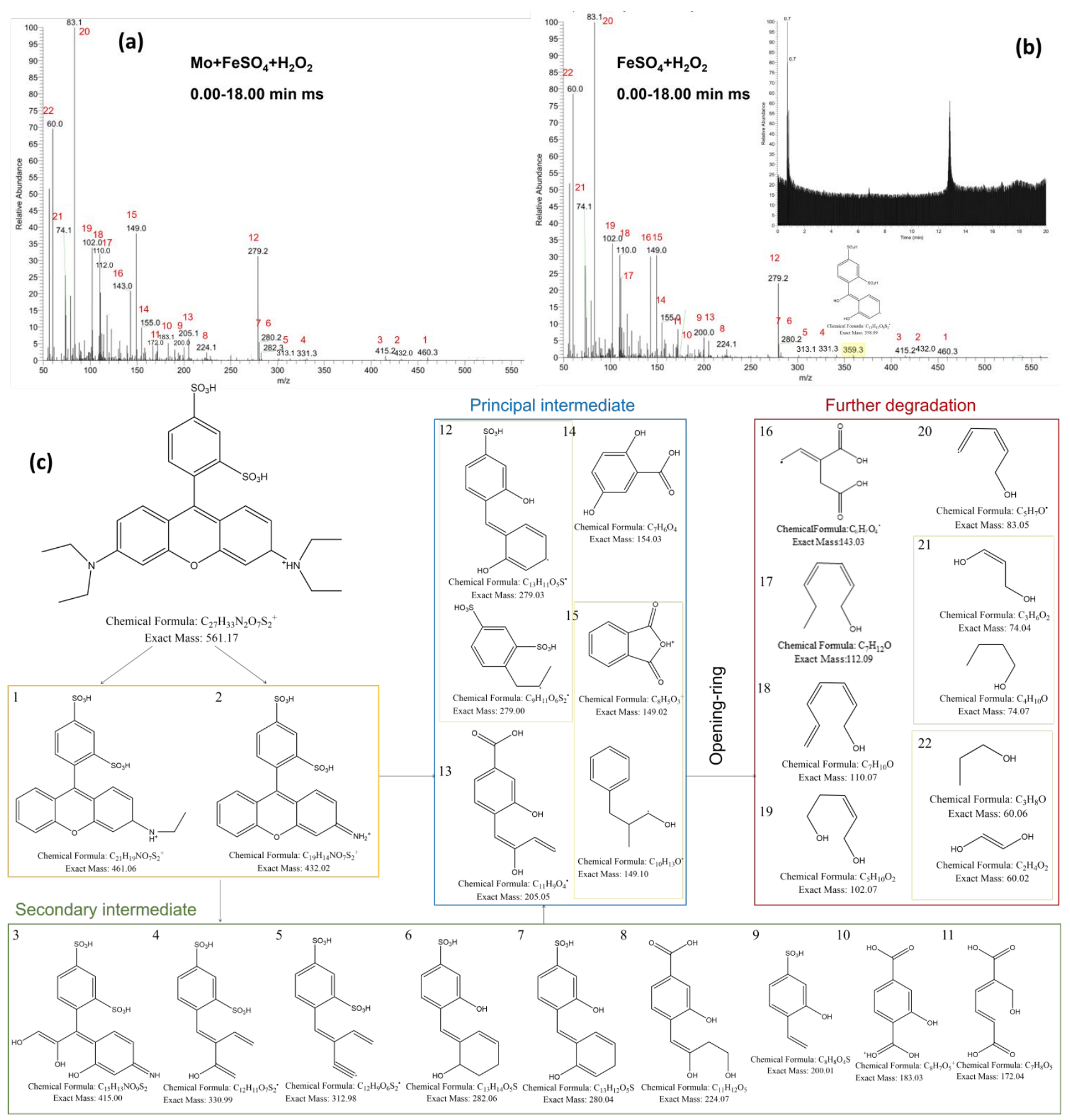

Figure S5. Main products of the degradation of L-RhB at $5 \mathrm{~min}$ in (a) Mo cocatalytic system and (b) conventional Fenton system detected by HPLC-MS method. (c) Proposed degradation pathway of L-RhB in Mo co-catalyst Fenton system.

To confirm the degradation process of L-RhB in Mo co-catalytic Fenton system, we analyzed the MS from 1-18 min. As shown in Figure S5a and S5b, several second intermediate products except in the five time periods can also be inferred. Based on the overall MS results, we could infer the degradation process of L-RhB in Mo co-catalytic Fenton process, which is shown in Figure S5c. 
L-RhB could be degraded to macromolecular products 1 and 2, and then further degraded to small molecules 3-22. Based on the relative peak intensity, it is inferred that the content of 3-11 is small, and 12-15 are the main intermediate product, which would be further decomposed into 16-22 by the ring-open reaction. Finally, these small molecular acids and alcohols will be further converted into $\mathrm{CO}_{2}$ and $\mathrm{H}_{2} \mathrm{O}$. Compared with conventional Fenton reaction system, there was no significant difference between the Fenton reaction system and Mo cocatalytic Fenton system in the degradation of L-RhB, except for the relative amounts of intermediate products. In addition, there is an intermediate with low content in the conventional Fenton system, whose $\mathrm{m} / \mathrm{z}$ is 359 , corresponding to $\mathrm{C}_{13} \mathrm{H}_{11} \mathrm{O}_{8} \mathrm{~S}_{2}$. 


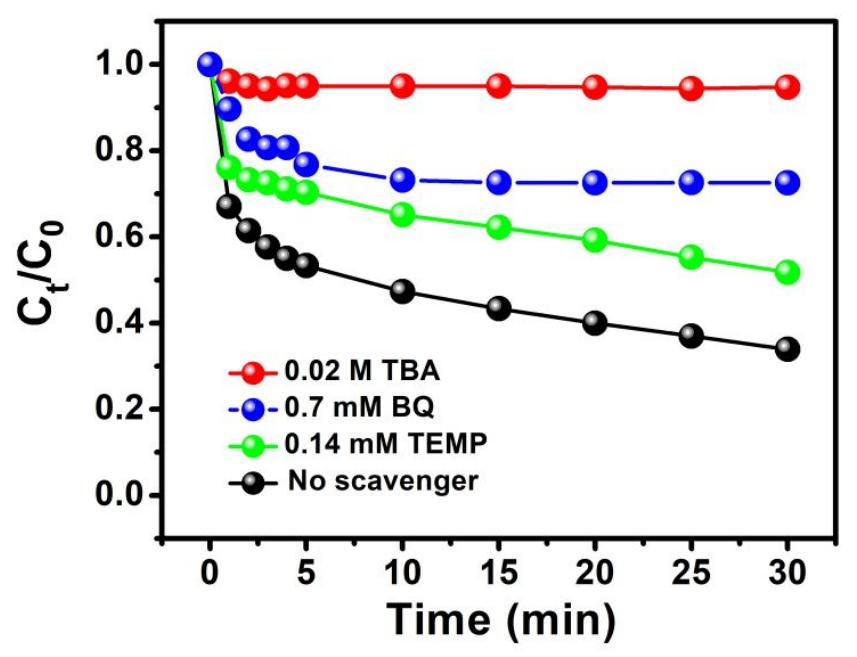

Figure S6. Degradation curve of L-RhB under different conditions in the presence of different radical scavengers including tert butyl alcohol (TBA, $0.02 \mathrm{M})$, p-benzoquinone (BQ, $0.7 \mathrm{mM})$ and 2,2,6,6-tetramethylpiperidine (TEMP, $0.14 \mathrm{mM}$ ) for the quenching of $\bullet \mathrm{OH}, \cdot \mathrm{O}_{2}^{-}$and ${ }^{1} \mathrm{O}_{2}$, respectively, over the conventional Fenton system: $20 \mathrm{mg} \cdot \mathrm{L}^{-1} \mathrm{Fe}\left(\mathrm{SO}_{4}\right) \cdot 7 \mathrm{H}_{2} \mathrm{O}, 0.4 \mathrm{mM} \mathrm{H}_{2} \mathrm{O}_{2}$, and the $\mathrm{pH}=3.8$. 

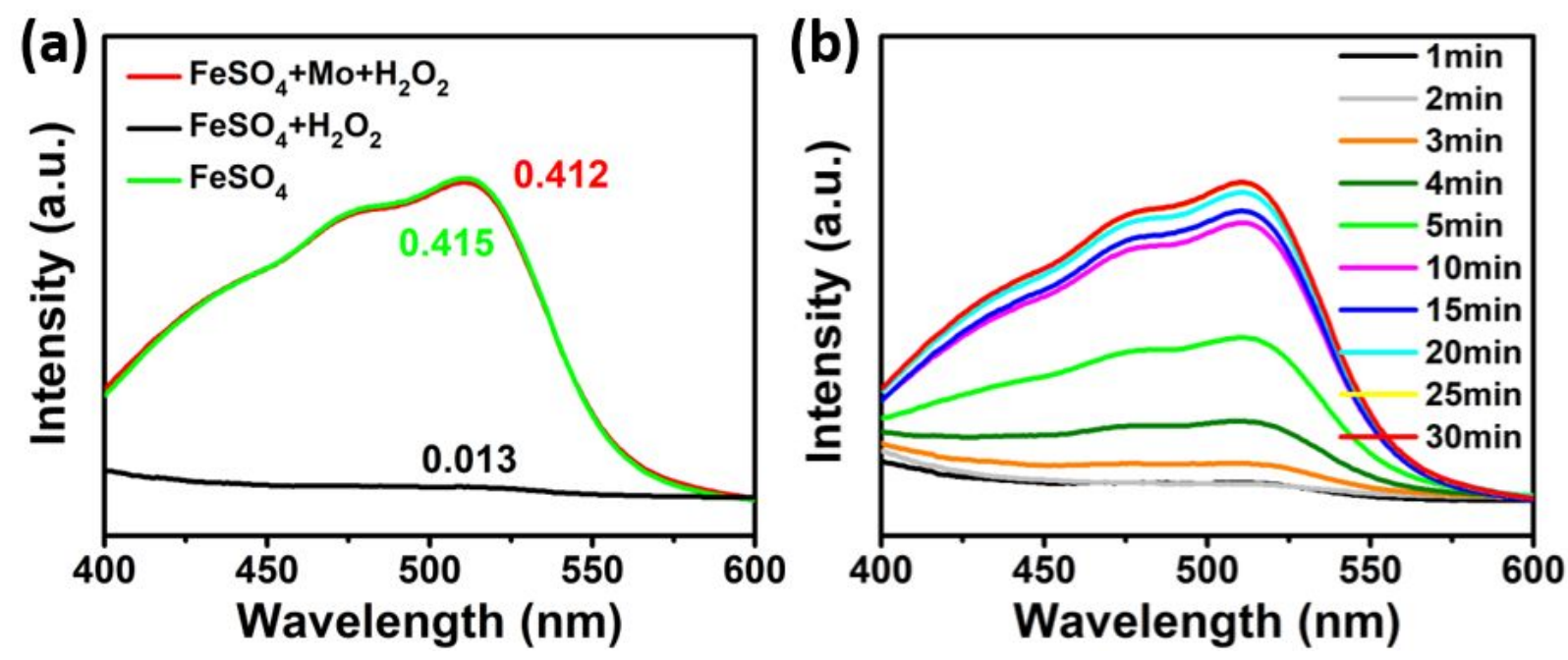

Figure S7. UV-vis spectra of the $\mathrm{Fe}^{2+}$ - phenanthroline complex at (a) different conditions in $30 \mathrm{~min}$ and (b) different times with Mo powder present. 


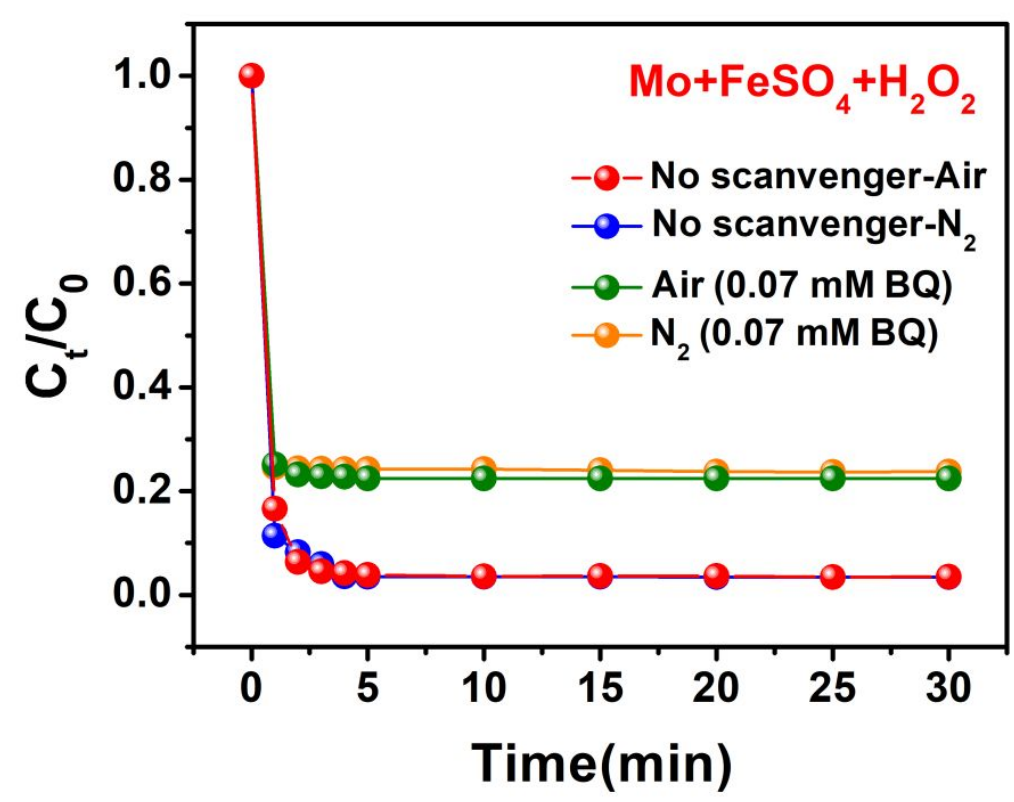

Figure S8. Degradation of L-RhB in Mo cocatalytic Fenton systems under $\mathrm{N}_{2}$ protection and in the presence of different radical scavengers.

To investigate the effect of $\mathrm{O}_{2}$ in the air on the generation of $\bullet \mathrm{O}_{2}{ }^{-}$, we performed the degradation test in $\mathrm{N}_{2}$ protection. Seen from Figure S8, the activity of Mo cocatalytic Fenton reaction has no obvious difference before and after removed $\mathrm{O}_{2}$. At $\mathrm{N}_{2}$ protection, the addition of $\mathrm{BQ}$ as a capture agent still have a significant inhibitory effect, and the degradation rate has no difference from the degradation in air. There are two reasons leading to this result. Firstly, amount of $\mathrm{O}_{2}$ dissolved in water cannot be completely removed, which could be transferred to $\cdot \mathrm{O}_{2}{ }^{-}$in the presence of $\mathrm{Fe}^{2+}$. Secondly, oxygen adsorbed on the surface of molybdenum powder is the main source of $\bullet \mathrm{O}_{2}$. 


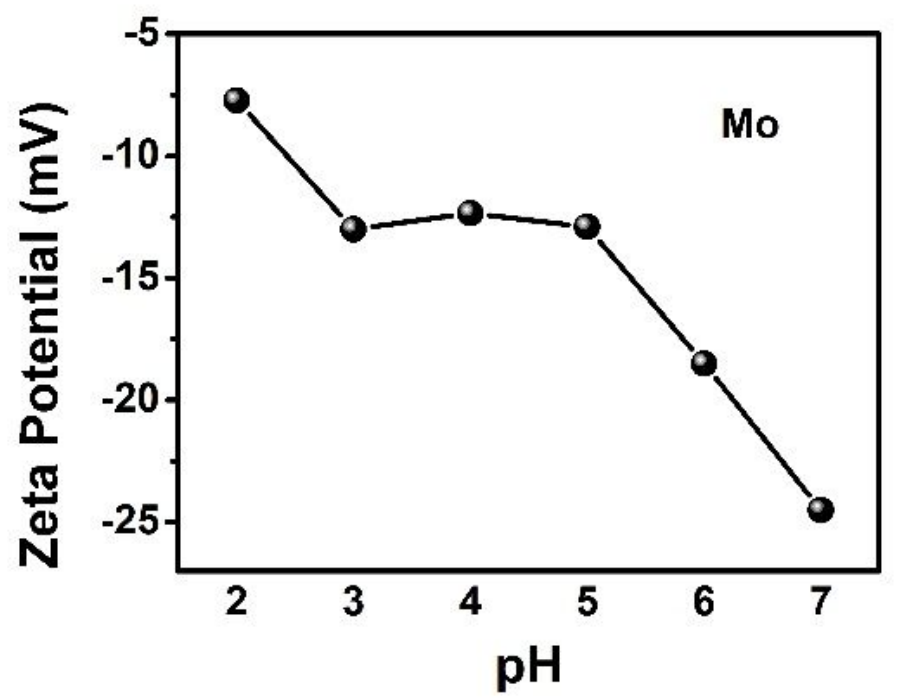

Figure S9. Zeta potential at different $\mathrm{pH}$ of Mo powder $\left(1 \mathrm{mg} \cdot \mathrm{mL}^{-1}\right)$ at room temperature. 


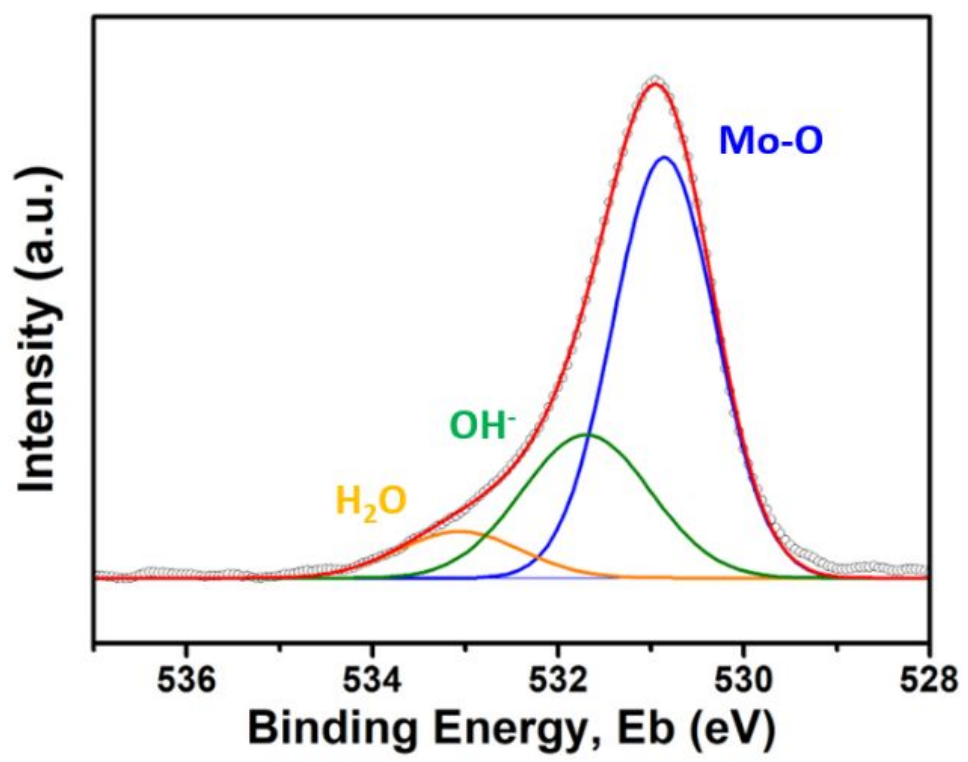

Figure S10. Typical O 1s XPS spectrum obtained from Mo powder surface and the peaks corresponding to $\mathrm{Mo}-\mathrm{O}, \mathrm{OH}^{-}$and $\mathrm{H}_{2} \mathrm{O} .{ }^{1}$ 


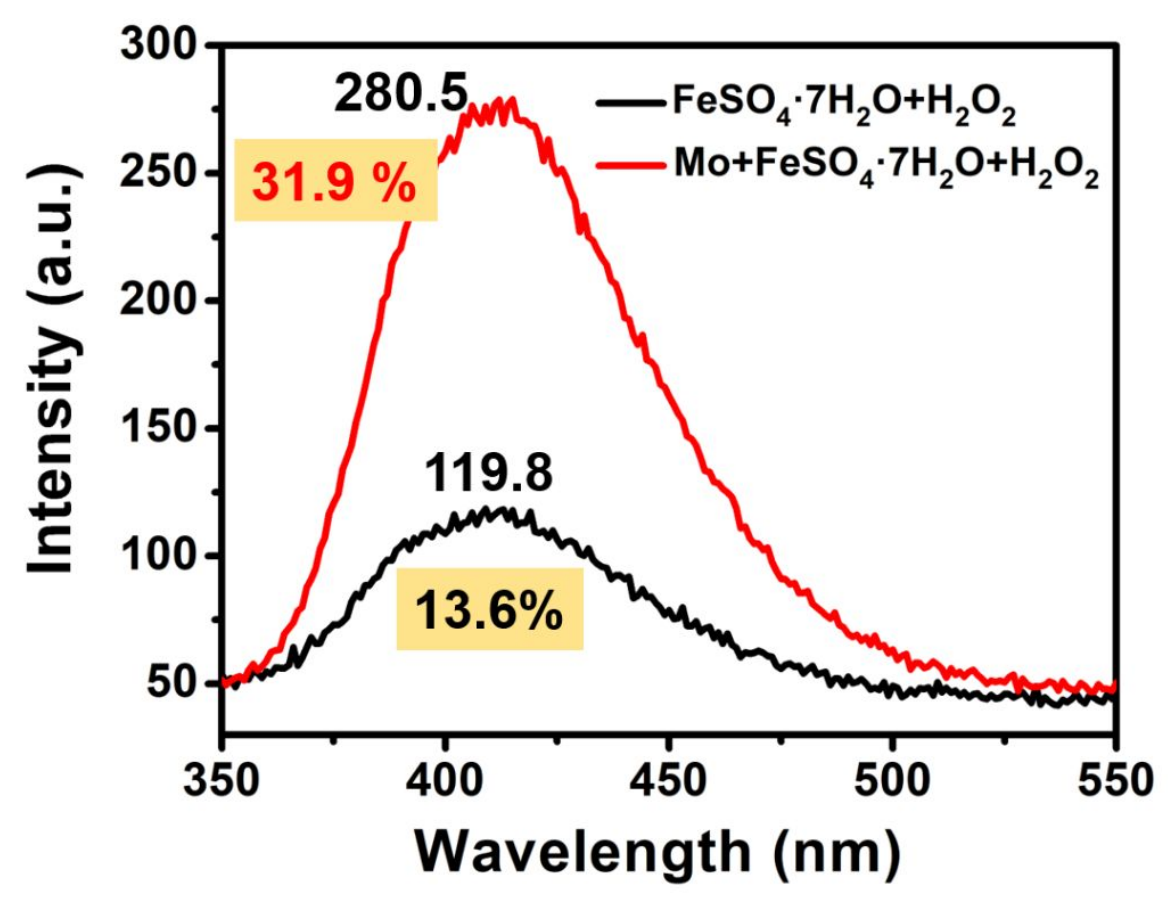

Figure S11. Photoluminescence spectra of benzoic acid mixed with different solutions at $30 \mathrm{~min}$.

The decomposition efficiency of $\mathrm{H}_{2} \mathrm{O}_{2}$ in the Fenton reaction was measured by recording the increase in the photoluminescence (PL) signal of hydroxybenzoic acid resulting from the capture of free radicals by benzoic acid. It was employed the heating treatment $\left(90{ }^{\circ} \mathrm{C}\right.$ for 2 hours) causing 0.4 $\mathrm{mM} \mathrm{H} \mathrm{H}_{2} \mathrm{O}_{2}$ to completely decompose into free radicals. The decomposition efficiency of $\mathrm{H}_{2} \mathrm{O}_{2}$ in the Mo co-catalytic Fenton can be as high as 55.8\% (490.3/878.9 $\times 100 \%)$, which is much higher than the yield of $23.1 \%(203.3 / 878.9 \times 100 \%)$ for the conventional Fenton in the absence of Mo. 


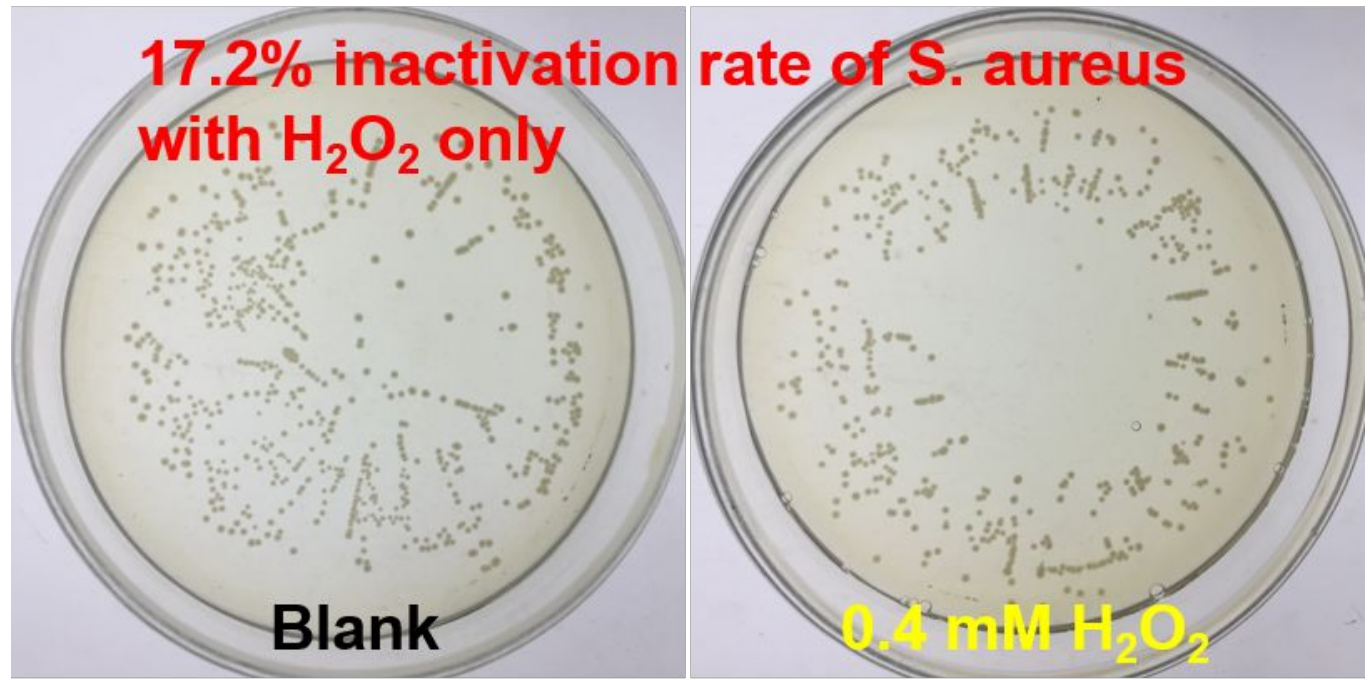

Figure S12. Images of the inactivation of $S$. aureus in the presence of $0.4 \mathrm{mM} \mathrm{H}_{2} \mathrm{O}_{2}$ only. 

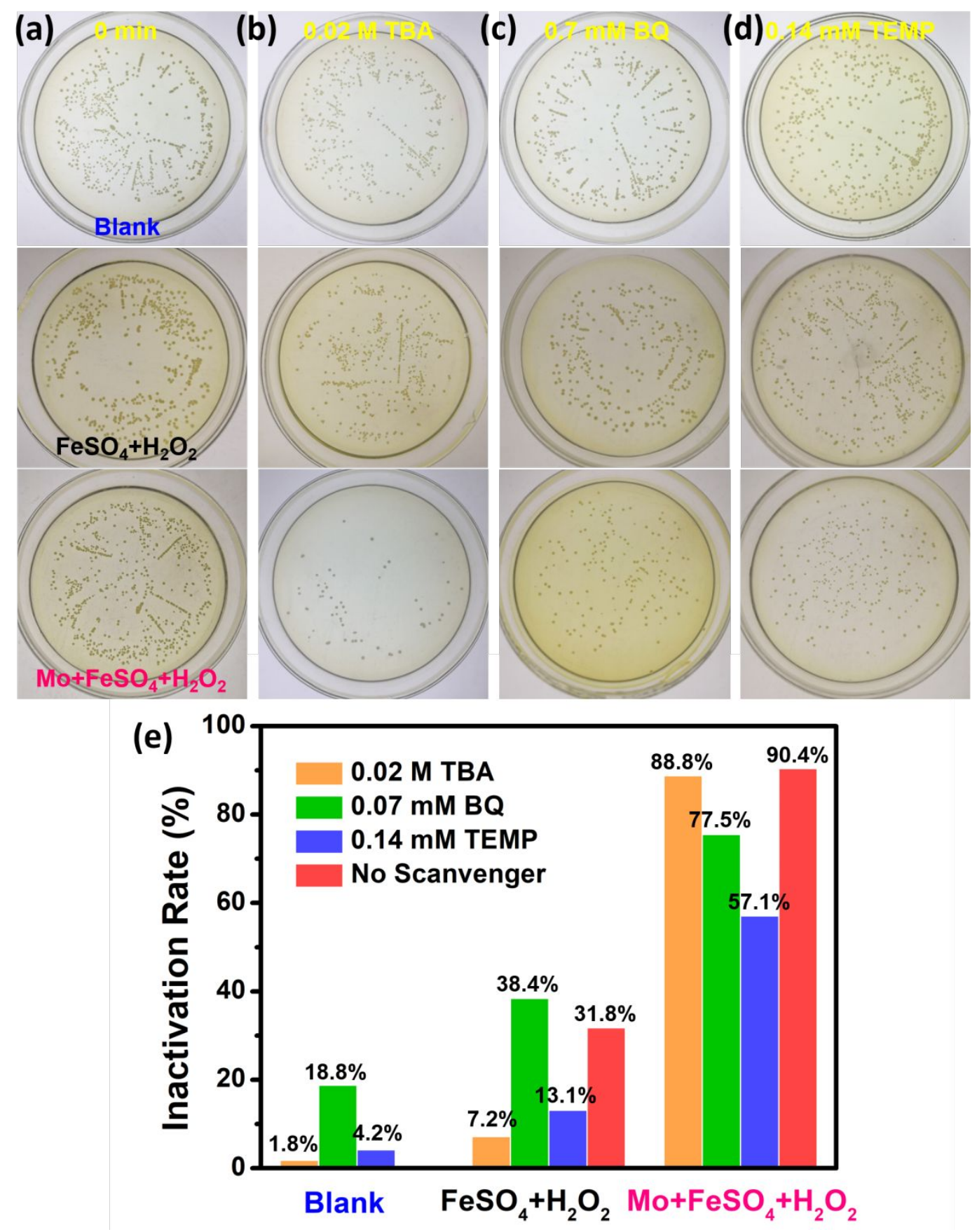

Figure S13. Images of the inactivation of $S$. aureus by different Fenton systems in the presence of different radical scavengers. (a) Without any scavengers, (b) tert butyl alcohol (TBA), (c) p-benzoquinone (BQ) and (d) 2,2,6,6-tetramethylpiperidine (TEMP) for the quenching of $\cdot \mathrm{OH}, \cdot \mathrm{O}_{2}{ }^{-}$ and ${ }^{1} \mathrm{O}_{2}$, respectively $\left(20 \mathrm{mg} \cdot \mathrm{L}^{-1} \mathrm{Fe}\left(\mathrm{SO}_{4}\right) \cdot 7 \mathrm{H}_{2} \mathrm{O}, 0.4 \mathrm{mM} \mathrm{H} \mathrm{H}_{2}, 50 \mathrm{mg} \cdot \mathrm{L}^{-1}\right.$ Mo powder, and the $\mathrm{pH}=3.8)$

Fenton and Mo cocatalytic Fenton system were applied in the disinfection experiment, and various radicals working. The main active species for the inactivation of $\mathrm{S}$. aureus in different system are 
determined by adding quencher. TBA, BQ and TEMP were used as the scavenger to capture $\bullet \mathrm{OH}$, - $\mathrm{O}_{2}{ }^{-}$and ${ }^{1} \mathrm{O}_{2}$. As shown in Figure $\mathrm{S}$ e, the blank experiment shows that the disinfection abilities of TBA and TEMP are very weak, but the effect of BQ is obvious. The addition of BQ could affect the disinfection, but does not affect the judgment of active species. In conventional Fenton system, the addition of TBA could significantly inhibit the disinfection ability. BQ has enhanced the disinfection ability, which is causing from the $\bullet \mathrm{OH}$ and BQ. in Mo cocatalytic Fenton system, TEMP showing significant inhibition of disinfection and BQ also showing a certain inhibitory effect. Then, we could come to the conclusion, in conventional Fenton system, $\bullet \mathrm{OH}$ is the most important radical, while the - $\mathrm{O}_{2}{ }^{-}$and ${ }^{1} \mathrm{O}_{2}$ are the main radical of Mo cocatalytic Fenton system in the disinfection experiment. 


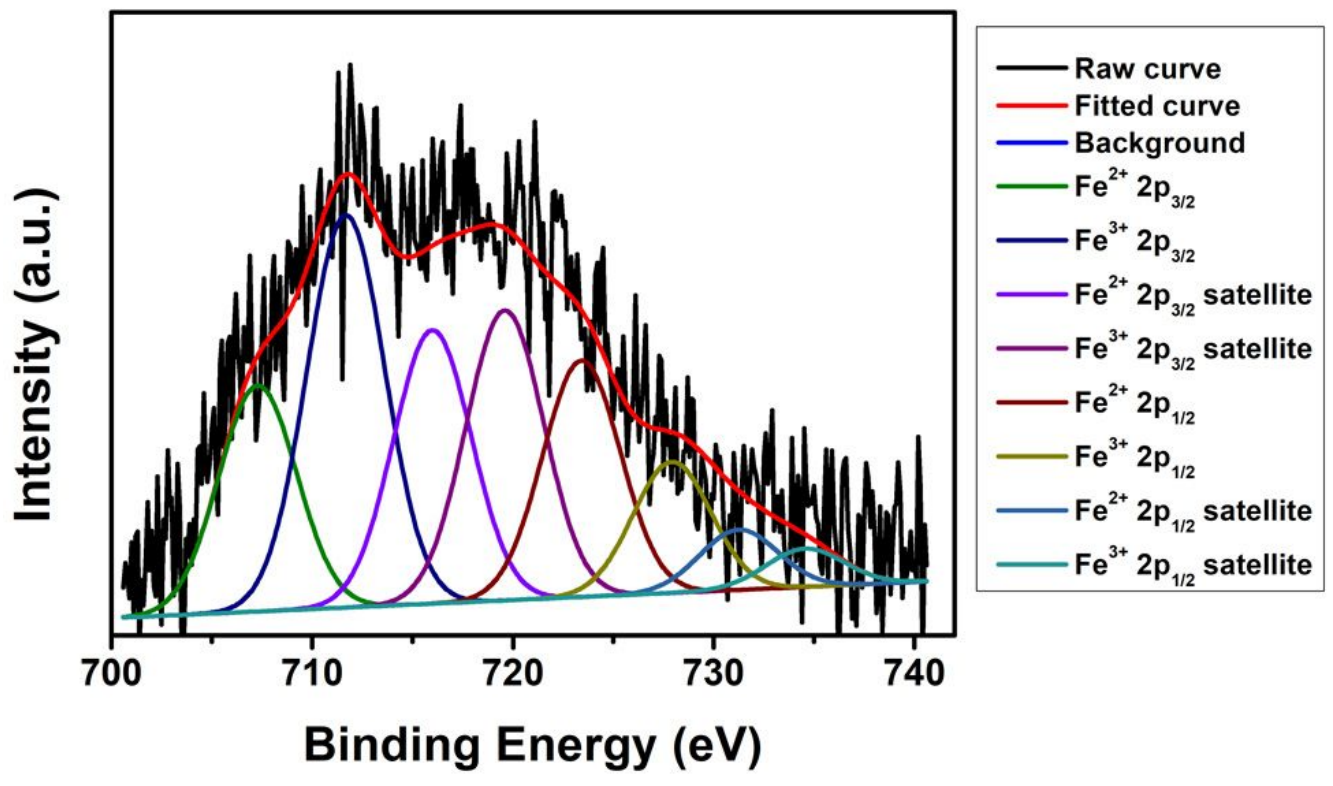

Figure S14. XPS spectra for Fe $2 p$ of Mo recycle. ${ }^{2}$ 

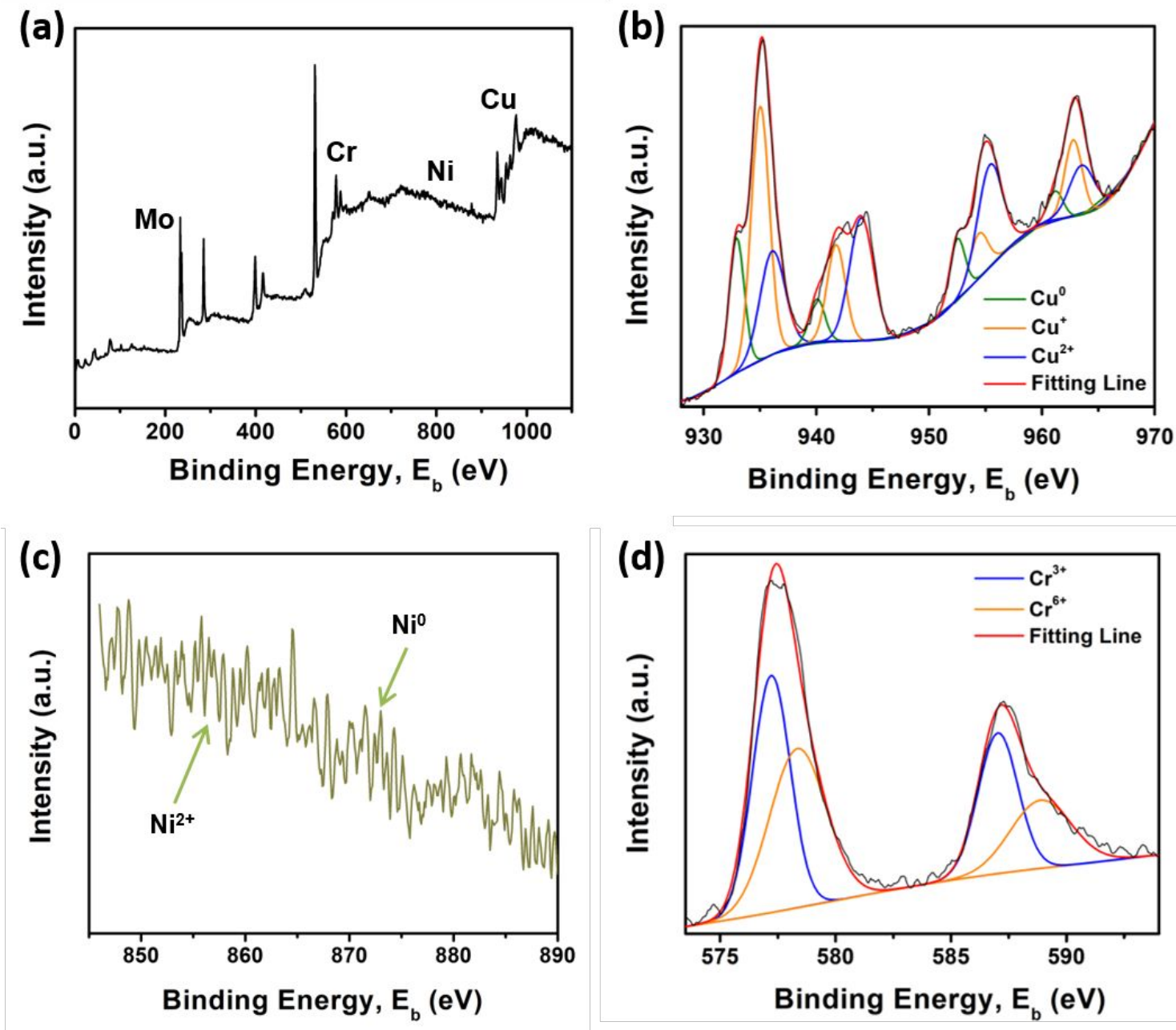

Figure S15. XPS spectra of (a) wide-scan, (b) Cu 2p, (c) Ni 2p and (d) Cr 2p. ${ }^{3-6}$ 
(a)

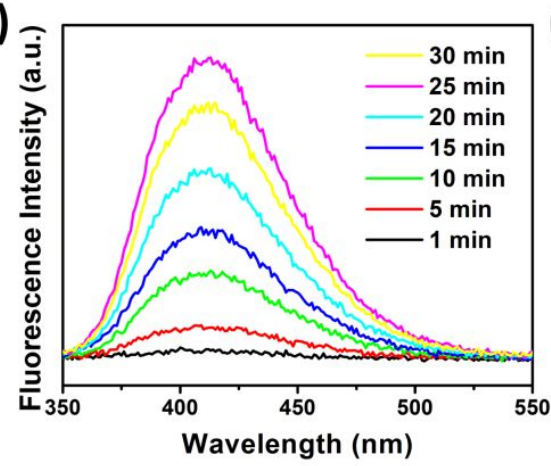

(c)

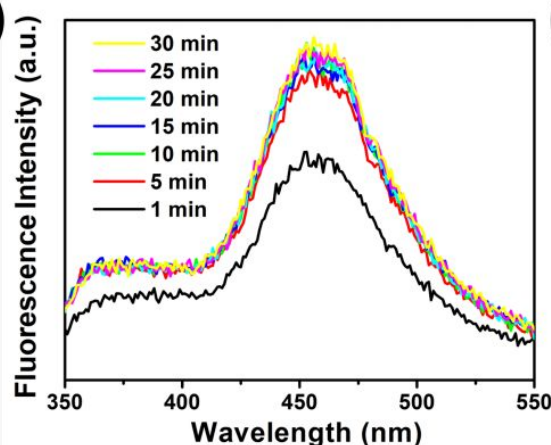

(e)

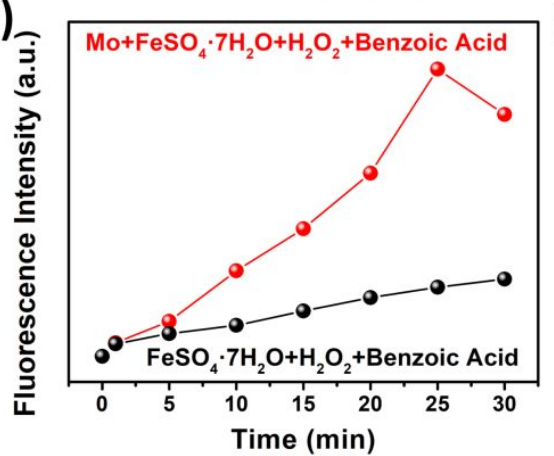

(g)

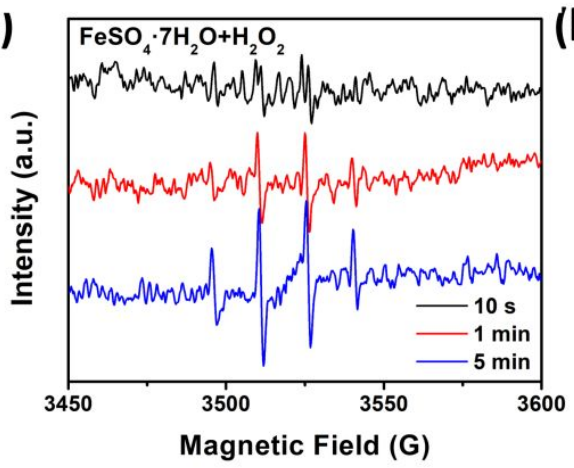

(b)

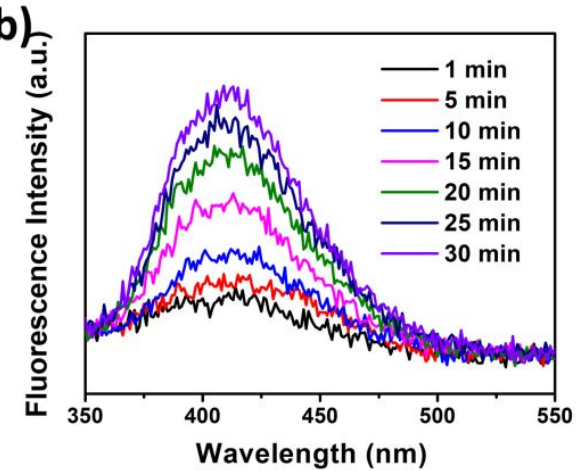

(d)

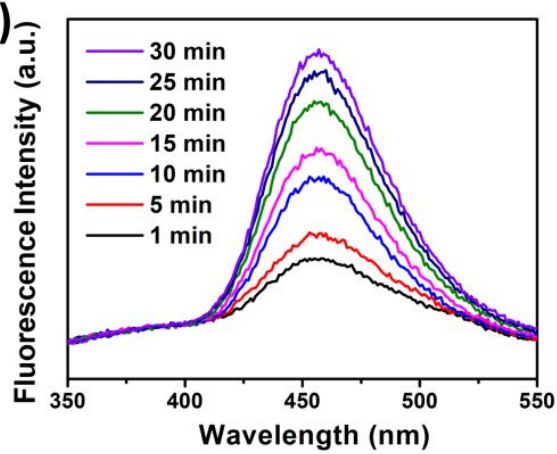

(f)

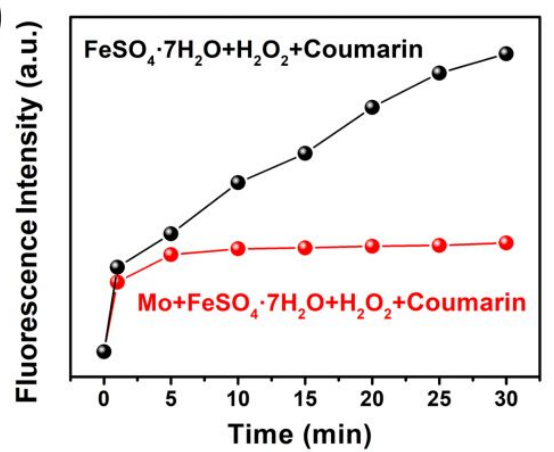

(h)

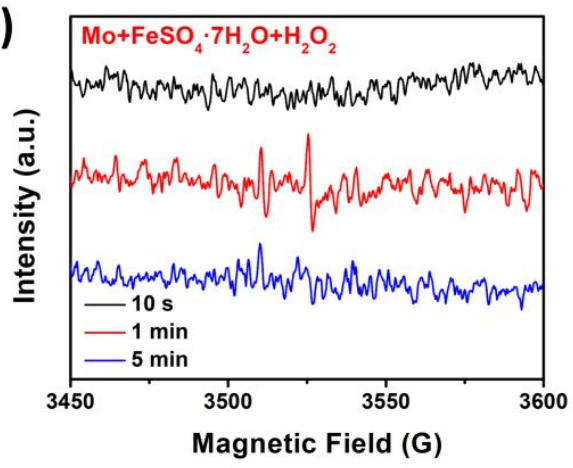

Figure S16. Photoluminescence spectra of ( $a$ and b) benzoic acid and (c and d) coumarin mixed with Mo cocatalytic (a, c) and conventional Fenton (b, d) systems after reaction for different time. And the related fluorescence intensity at different systems with (e) benzoic acid and (f) coumarin. EPR spectra for the detection of $\bullet \mathrm{OH}$ of $(\mathrm{g})$ in conventional Fenton and Mo cocatalytic $(\mathrm{h})$ systems at various reaction time (10 s, $1 \mathrm{~min}, 5 \mathrm{~min})$. 

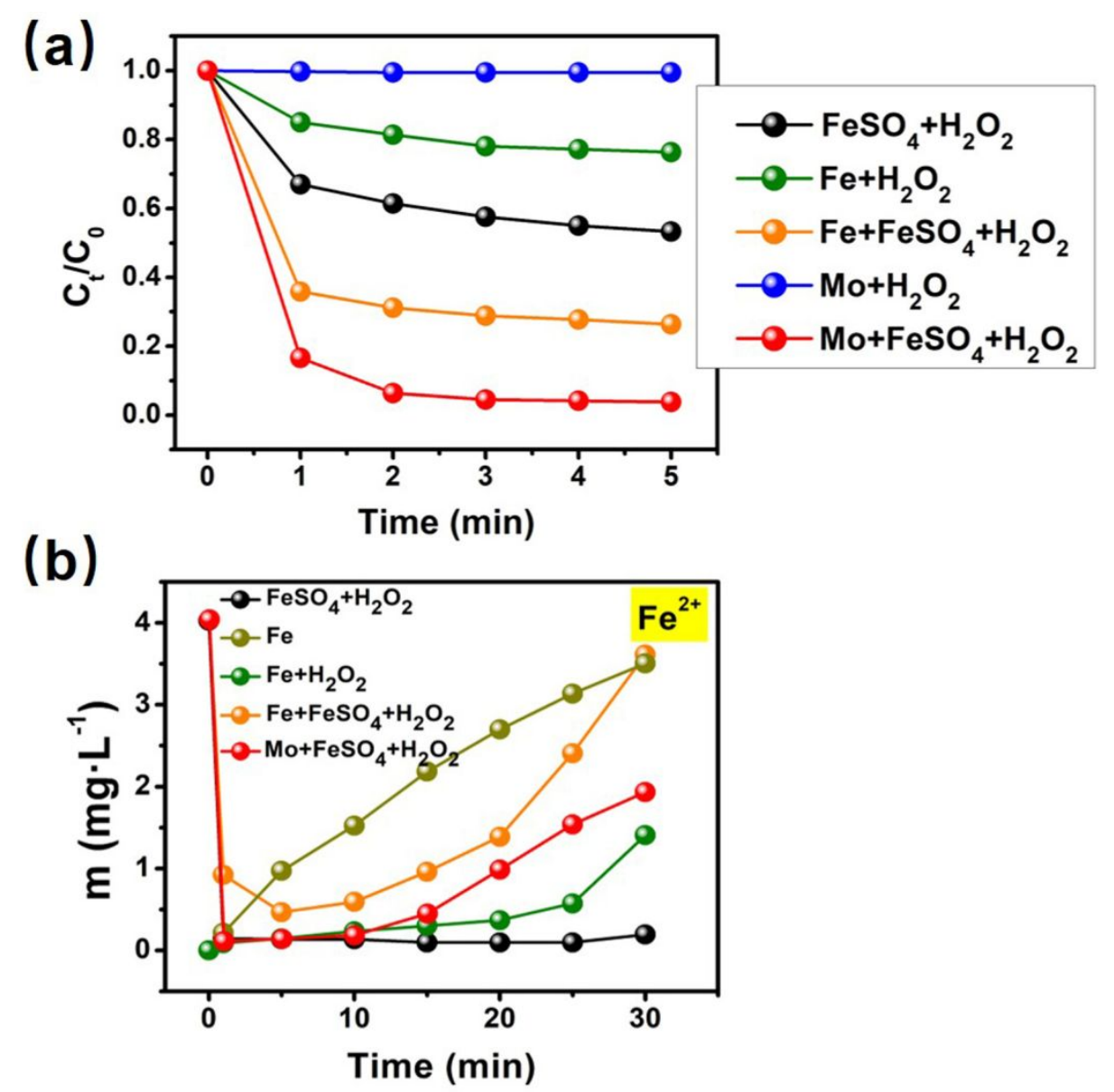

Figure S17. (a) Comparison of the activity between molybdenum powder co-catalytic Fenton and iron powder co-catalytic Fenton $\left(20 \mathrm{mg} \cdot \mathrm{L}^{-1} \mathrm{Fe}\left(\mathrm{SO}_{4}\right) \cdot 7 \mathrm{H}_{2} \mathrm{O}, 0.4 \mathrm{mM} \mathrm{H} \mathrm{O}_{2}, 50 \mathrm{mg} \cdot \mathrm{L}^{-1} \mathrm{Fe}\right.$ powder, and the $\mathrm{pH}=3.8$ ). (b) $\mathrm{Fe}^{2+}$ concentration detection in the solution over different Fenton systems $(\mathrm{pH}=3.8)$.

\section{References:}

1. Hanawa, T.; Hiromoto, S.; Asami, K., Characterization of the surface oxide film of a Co-Cr-Mo alloy after being located in quasi-biological environments using XPS. Appl. Surf. Sci. 2001, 183, $68-75$.

2. Tang, R.; Jiang, C.; Qian, W.; Jian, J.; Zhang, X.; Wang, H.; Yang, H., Dielectric relaxation, resonance and scaling behaviors in $\mathrm{Sr}_{3} \mathrm{Co}_{2} \mathrm{Fe}_{24} \mathrm{O}_{41}$ hexaferrite. Sci. Rep. 2015, 5, 13645.

3. Biesinger, M. C.; Lau, L. W. M.; Gerson, A. R.; Smart, R. S. C., Resolving surface chemical states in XPS analysis of first row transition metals, oxides and hydroxides: $\mathrm{Sc}, \mathrm{Ti}, \mathrm{V}, \mathrm{Cu}$ and $\mathrm{Zn}$. Appl. Surf. Sci. 2010, 257, 887-898.

4. Ren, Z.; Xu, X.; Wang, X.; Gao, B.; Yue, Q.; Song, W.; Zhang, L.; Wang, H., FTIR, Raman, and XPS analysis during phosphate, nitrate and $\mathrm{Cr}(\mathrm{VI})$ removal by amine cross-linking biosorbent. $J$. Colloid Interface Sci. 2016, 468, 313-323. 
5. Singh, H.; Rai, A.; Yadav, R.; Sinha, A. K., Glucose hydrogenation to sorbitol over unsupported mesoporous Ni/NiO catalyst. Mol. Catal. 2018, 451, 186-191.

6. Wang, Y.; Lü, Y.; Zhan, W.; Xie, Z.; Kuang, Q.; Zheng, L., Synthesis of porous $\mathrm{Cu}_{2} \mathrm{O} / \mathrm{CuO}$ cages using $\mathrm{Cu}$-based metal-organic frameworks as templates and their gas-sensing properties. $J$. Mater. Chem. A 2015, 3, 12796-12803. 